\title{
High-temperature thermomechanical treatment of hollow track pins of track-type machines
}

\author{
Andrei Zasypkin ${ }^{1, *}$, Vyacheslav Dement'yev ${ }^{1}$, and Mikhail Sterkhov ${ }^{1}$ \\ ${ }^{1}$ FGBUN Institute of Mechanics, the Ural Branch of the Russian Academy of Sciences, Izhevsk, the Russian Federation
}

\begin{abstract}
Very often the track pins of heavy-loaded track-type machines have insufficient fatigue safety margin, which causes their frequent breakage. One of the most rational solutions of the problem is the use of the high-temperature thermomechanical treatment of hot-rolled tubular billets for track pins. The analysis of the investigation results and engineering developments shows the possibility of improving the performance characteristic of hollow items (shafts, axis pins, track pins for a caterpillar mover, torsion suspensions of an undercarriage, etc.) by combining the thermomechanical treatment strengthening, various methods for improving the quality of the surface of tubular billets and the application of developed technological schemes in the factories producing tubular billets and items with diameter of $\varnothing 10 \div 60 \mathrm{~mm}$ and the parameters of safety margin, precision and roughness required for the durability of the items.
\end{abstract}

\section{Introduction}

The application of the tubular design of the track pins for a caterpillar chain in Russia is very limited. At present, hot-rolled tubular billets are used in track-type machines with an open hinge, where the cross-section area of the track pins provides the transverse strength with the safety margin of 2-3 in the absence of the limited weight requirements for the track pins (the track pins of industrial tractors T-330, T-500).

A significant increase in loading of modern tracktype machines (TTM) connected with the requirement on the improvement of their technical features leads to high loading of the undercarriage parts. A track pin is an undercarriage part which fails very often and limits the life of the machine. The use of hollow track pins solves a number of problems connected with their performance characteristic; however, the use of the tubular design leads to the decrease in the transverse strength of the track pins. One of the ways for improving the transverse strength and performance characteristic of the hollow track pins operating in the condition of asymmetric constant-sign bending loading is when in the technological process of the track pins production, a strengthening high-temperature thermomechanical treatment (HTMT) with the deformation of a hot-rolled billet by spiral reduction (SR) with the simultaneous improvement of the quality of both the external and internal working surface is used [1]. The process of HTMT+SR is a complex of continuous actions on the tubular billet consisting of high-frequency heating to the temperatures higher than the austenization temperature, deformation in three tangentially placed idle rollers, and cooling in a sprayer device [2].

It is known that HTMT positively influences the mechanical characteristics of steels (static and cyclic strength, toughness and ductility, wear resistance, etc.). Unfortunately, the use of this high-efficiency treatment for improving the operating reliability of the machine parts is difficult due to its peculiar features; the anisotropy of properties and high hardness of a material make it difficult to process parts by cutting. The development and application of the HTMT technology is possible when the above peculiar features are taken into account at the stage of the designing of parts and development of the technology for their fabrication.

Earlier, all the investigations were mainly conducted for track pins with solid cross-section. The creation of HTMT makes it possible to use a hollow track pin design after a hot-rolled extra thick-walled billet has been obtained instead of a billet with the solid cross-section.

\section{Materials and methods}

The choice of a material is determined by the operational requirements to the parts. In the investigation of the purpose and the functional stress of the track pins for track-type machines, alloy steels 50G, 55HGR and 38HS for an open hinge operating in the conditions of abrasion wear and alloy steels 38HS and 30HGSN2A for a rubber-metal hinge undergoing high static and cyclic loading were used.

Based on the numerous investigations of the use of track pins from various steels conducted in VNIIStal [Research Institute of Steel] (Moscow) and the results of the investigations of the thermomechanical treatment (TMT) of track pins with the solid cross-section [1], steels 30HGSN2A and 38HS could be recommended for investigating TMT tubes for hollow track pins.

However, steel $38 \mathrm{HS}$ is not used for the tube production and the testing results [3] showed poor durability of the track pins from steel $38 \mathrm{HS}$ in the

\footnotetext{
Corresponding author: oka592@rambler.ru
} 
condition of constant-sign asymmetric bending loading; therefore, we have chosen steel 30HGSN2A for our studies and conducted the comparative studies of both steels.

Steel 30HGSN2A has good technological and service properties, a good combination of strength and ductility after quenching and low-temperature tempering $\left(\sigma_{\mathrm{B}}=\right.$ $\left.1700-1800 \mathrm{MPa} ; \delta=12 \% ; \mathrm{KCU}=1.1 \mathrm{MJ} / \mathrm{m}^{2}\right)$, and high stability of austenite at overcooling.

The chemical composition of steels 30HGSN2A and $38 \mathrm{HS}$ used for fabricating track pins corresponds to GOST 8294-71 and GOST 7860-71, respectively.

As initial billets, hot-rolled tubes with diameters of $\varnothing$ 50 and $\varnothing 40 \mathrm{~mm}$ according to GOST 2590-76 were used for making track pins $\varnothing 30 \times 15 \mathrm{~mm}$ and $\varnothing 22 \times 10 \mathrm{~mm}$, respectively. The technological fabrication process is described in [1] in details. When the technology was adhered exactly, the hollow track pins made in accordance to the technology showed satisfactory results during bench tests and roadormance trials.

\section{Results and discussion}

In the process of the fabrication of the pilot batches of hollow track pins strengthened by HTMT, the quality level of the billets and items is studied. Based on the results of the studies, the dependences of the service properties and the quality level on the production process conditions are established. All the quality levels of the tubular goods can be divided into three groups.

The first group is the quality level geometrically characterizing a tube: the accuracy of the external diameter $\left(\mathrm{D}_{\text {external }}\right)$ and the thickness of the wall $\left(\mathrm{W}_{\mathrm{T}}\right)$.

The second group of the quality levels characterizes the tube external condition, namely, the quality of the ends of the tubes, the quality of the outer and inner surfaces, and the denseness of the entire body of the tube (cracks, scale residue, etc, GOST 20847-75).

The third group of the quality levels is used for characterizing physicochemical properties of the tube: strength, ductility, chemical activity, etc.; they are mainly dependent on the tube material properties.

The accuracy evaluation is made for the tubes produced according to two manufacturing schemes of calibration with the use of deformation shown in Fig. 1.

The deformation on the triblet (Fig. 1a) is more labor intensive and it is used in the production of tubes with the internal diameter of $\varnothing 10 \mathrm{~mm}$ and smaller than that. The tubes with a diameter larger than $10 \mathrm{~mm}$ are processed according to the second scheme (Fig. 1b).

The statistical estimation of the accuracy of the tube wall thickness and diameter is conducted according to the method of the Chelyabinskiy tube-rolling mill [3]. It should be noted that the final difference in the tube wall thickness strongly depends on the initial difference in the wall thickness of the billets after processing on the piercing mill. One of the ways for decreasing the difference in the tube wall thickness is the tube straightening by tube cross-roll straighteners of the type RVV $320 \times 4$ after sizing reduction (due to the decrease of the tube radial runout) before the turning machining of the external diameter.
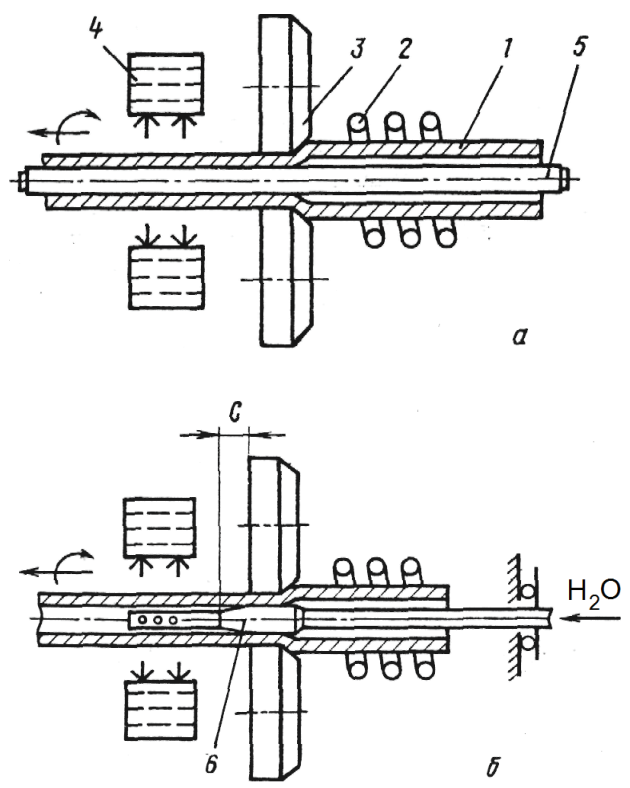

Fig. 1. The manufacturing schemes of the tube deformation on the triblet (a) and on the stub mandrel (b): 1 - a billet; 2 - an induction coil; 3 - deforming rollers; 4 - a sprayer; 5 - a triblet; 6 - a stub mandrel

The comparison of the two schemes of the calibration by deformation (Fig. 1) shows that at the processing of the tubes with $D_{\text {external }}=22 \mathrm{~mm}$ and $\mathrm{d}_{\text {internal }}=10 \mathrm{~mm}$ according to the first scheme (Fig. 1a), the total deviation $\omega_{\Sigma}$ of the external diameter is smaller than for the same tubes processed according to the second scheme (Fig. 1b). However, the internal diameter obtained with the use of the second scheme is more exact.

The calibration of the rolled tubular products in the deformation mode provides the geometry fidelity at the level 11 of the quality class according to GOST 25347 82.

The investigation of the surface quality of the tubular billets shows that for obtaining a defect-free strengthened tubular billet it is necessary to include the process of removing a defective layer to the depth of $0.8 \ldots 1.0 \mathrm{~mm}$ into the manufacturing process prior to the HTMT process or in the HTMT process and the followon operations of grinding and clearing with an abrasive tool to the depth of $0.7 \ldots 0.8 \mathrm{~mm}$.

The influence of the HTMT conditions on the steel mechanical properties has been studied in details in the papers by O.I. Shavrin, V.B. Dement'yev [1, 3] and other researchers. However, the influence of the technology of processing and the degree of the deformation at the straining of tubes on the steel mechanical properties is also of a certain interest [3].

\section{Bench and performance testing}

In the present paper, the results are presented of the investigations of hollow track pins from TMT rolled products made from steels $38 \mathrm{HS}$ and $30 \mathrm{HGSN} 2 \mathrm{~A}$ 
(GOST 4543-78) with pressure shaping and without pressure shaping conducted according to the method developed in the Research Institute of Steel (Moscow). The loading conditions during bench testing are: $\sigma_{\max }=$ $800 \mathrm{MPa}$ and $\sigma_{\min }=200 \mathrm{MPa}$.

The testing results show that

- the durability of the track pins without pressure shaping made from steel 30HGSN2A exceeds the durability of the track pins from steel $38 \mathrm{HS}$ independent of the treatment conditions;

- the durability of the track pins without pressure shaping made from TMT tubular rolled products from steel $30 \mathrm{HGSN} 2 \mathrm{~A}$ is longer by a factor of four than that of the track pins from the same steel which has been quenched and tempered (319, 100 and 72, 400 cycles, respectively);

- the durability of the track pins with pressure shaping made from TMT rolled products from steel 30HGSN2A is $\sim 4$ times higher than that of the track pins with pressure shaping made from isothermally quenched steel 38HS $(1,073,000$ and 219, 400 cycles, respectively).

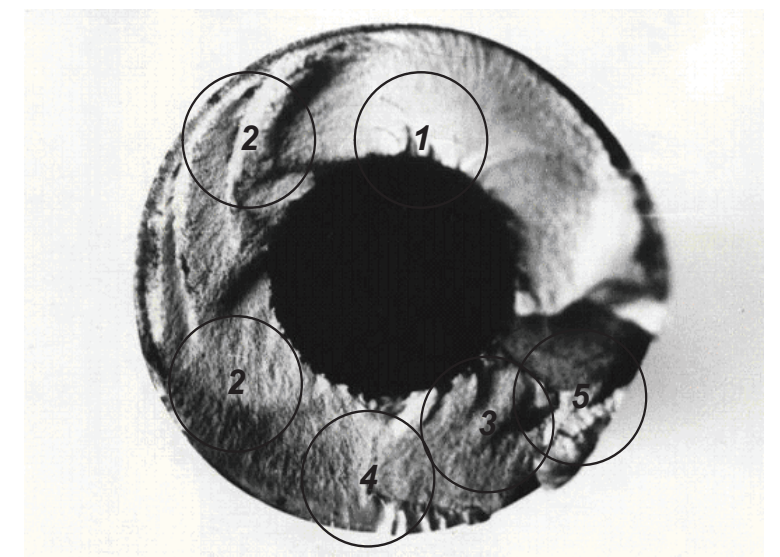

Fig. 2. A multinucleated crack on the internal surface of a hollow track pin undergone 305,000 loading cycles: 1 - region of the nucleation and development of the fatigue crack; 2 region of fibrous fracture; 3 - region of cut; 4 - region of herringbone and scar fracture; 5 - region of brittle fracture.

Figure 2 shows the view of the fracture of a benchtested hollow track pin.

Based on the extensive bench tests of the TMT hollow track pins $ø 22 \times 10 \mathrm{~mm}, \varnothing 30 \times 10 \mathrm{~mm}$, and $ø 30 \times$
$15 \mathrm{~mm}$ from steel $30 \mathrm{HGSN} 2 \mathrm{~A}$, the pilot batches of track pins have been fabricated. The performance testing of the products with the track pins fabricated according to the developed technology shows that in their characteristics, the hollow track pins are not inferior and, in a number of cases, are superior to the track pins with the solid cross-section fabricated by the conventional technology [1].

One of the conditions for improving the durability of a hollow part is the complete elimination of defects of the internal surface and its strengthening by the methods of the surface plastic deformation in the combination with the HTMT process. Because of the residual stresses appearing during strengthening and the necessity of the fulfillment of the requirement to strength balance, the optimal range of the ratio of $\mathrm{d}_{\text {internal }} / \mathrm{D}_{\text {external }}$ is within the limits of $0.4 \ldots 0.6$.

\section{Conclusions}

The technological process has been developed and tested for the fabrication of hollow track pins for track-type machines from an extra thick-walled hot-rolled tubular billet strengthened in the HTMT regime with better mechanical properties and longer durability in comparison with those of track pins fabricated with the use of conventional technology.

\section{References}

1. V.B. Dement'ev, O.I. Shavrin, L.N. Maslov, A.D. Zasypkin, Kachestvo pal'tsev trakov - osnova nadezhnosti $i$ dolgovechnosti gusenitsy (Izhevsk: IPM UrO RAN, 2009) ISBN 978-5-89238-102-4

2. A.D. Zasypkin, Uprochnenie trubchatykh zagotovok dlia izgotovleniia polykh pal'tsev trakov gusenichnykh mashin, Traktory i sel'khozmashiny № 7, pp. 38-41 (2010)

3. O.I. Shavrin, V.B. Dement'ev, L.N. Maslov, A.D. Zasypkin, Kachestvo poverkhnosti tsilindricheskikh izdelii s termomekhanicheskim uprochneniem (Izhevsk: IPM UrO RAN, 2006) ISBN 5-89238088-2 